\title{
A Hyperglycemic Blood Mimicking Fluid with Good Acoustic and Physical Properties for In-Vitro Ultrasound Flow Studies
}

Kyermang Kyense Dakok ( $\sim$ dakokkyense@gmail.com )

Universiti Sains Malaysia

\section{Z. Matjafri}

Universiti Sains Malaysia

Nursakinah Suardi

Universiti Sains Malaysia

Anil U.I Sirisena

Jos University Teaching Hospital

Ammar A. Oglat

The Hashemite University Zarga, Jordan

\section{Research}

Keywords: Propylene Glycol, D(+)-Glucose, Blood Mimicking Fluid, Physical Properties, Acoustic Properties, Ultrasound

Posted Date: January 15th, 2021

DOl: https://doi.org/10.21203/rs.3.rs-144195/v1

License: (c) (1) This work is licensed under a Creative Commons Attribution 4.0 International License. Read Full License 
7 Malaysia, 11800 Penang Malaysia.

8 and Ammar A. Oglat ${ }^{3}(\mathrm{PhD})$ University, Zarqa, Joradan.

3

4

5

16

7

TITLE: A Hyperglycemic Blood Mimicking Fluid with Good Acoustic and Physical Properties for In-Vitro Ultrasound Flow Studies

\section{RUNNING TITLE: Hyperglycemic Blood Mimicking Fluid}

Dakok K.K ${ }^{1 *(M S c), ~ M . ~ Z . ~ M a t j a f r i ~}{ }^{1}(\mathrm{PhD})$, Nursakinah Suardi ${ }^{1}(\mathrm{PhD})$, Sirisena U.A.I ${ }^{2}(\mathrm{PhD})$,

1.Department of Medical Physics and Radiation Science, School of Physics, Univirsti Sains

2. Department of Radiology, Jos University Teaching Hospital, Jos-Nigeria

3. Department of Medical Imaging, Faculty of Applied Medical Sciences, The Hashemite

Corresponding Author: dakokkyense@ gmail.com

$+60164693059$ 


\section{Abstract}

Background: A blood mimicking fluid (BMF) is made up of a mixture fluid and ultrasound scattering particles that stay neutrally buoyant in the fluid. For these particles to be able to remain suspended in the fluid, their density must be very close or equal to the density of the

22 mixture fluid and the BMF must also have its acoustic properties (speed of sound, attenuation and backscatter power) and physical properties (density and viscosity) close to the internationally acceptable standard. This paper introduces $\mathrm{D}(+)$-Glucose (DG) as an important component of a mixture fluid consisting of Propylene Glycol (PG) and water for preparing a hyperglycemic blood mimicking fluid (BMF). Methodology: The BMF was prepared by first preparing

27 different samples of ternary mixture fluids in which a fixed amount of PG was mixed with various amounts of water and DG to get a particular and suitable percentage combination that yielded a density similar to that of poly (4-methylstyrene) scatter particles. A required amount of the scatter particles was mixed with the suitable mixture fluid to form a BMF with good physical and acoustic properties accepted by the International Electrochemical Commission. Results: A very good BMF was produced consisting of $84 \%$ distilled water, $5 \%$ of PG and $11 \%$ of DG as the ternary mixture fluid mixed with $0.8 \%$ Poly (4-methylstyrene) scatter particles. It has a

34 density of $1.040 \mathrm{~g} / \mathrm{cm}^{3}$, viscosity of $4.30 \mathrm{mpa} . \mathrm{s}$, speed of sound of $1580 \mathrm{~m} / \mathrm{s}$ and attenuation of $350.017 \mathrm{~dB} / \mathrm{cm}$ at $5 \mathrm{MHz}$, having a good back scatter property. Conclusion: DG is a good 36 substance that forms part of the ternary mixture fluid for the preparation of a hyperglycemic 37 BMF with suitable physical and acoustic properties.

Key Words: Propylene Glycol; D(+)-Glucose; Blood Mimicking Fluid; Physical Properties;

39 Acoustic Properties; Ultrasound. 


\section{Introduction}

Human blood samples are difficult to handle in the laboratory as fluids for bench work studies because of the complexity of blood and for other health related worries. This has led to several researches to chemically prepare fluids that can closely mimic the acoustic and physical properties of real blood and can be used as a good replacement in preclinical experiments. Earlier blood mimicking fluids (BMF) were made of water mixed with cutting fluid and nylon as scatter particles (Rickey et al., 1995); glycerol, water, dextran, orgasol mixed with synperonic N surfactant as scatters and Sodium azide as a preservative (Ramnarine et al., 1998; Lubbers, 1999; Ramnarine et al., 2001; Browne et al., 2003; Harin \& Ince, 2004; Samavat \& Evans, 2006; Meagher et al., 2007). Other substances introduced as part of the BMF mixtures towards getting better acoustic and physical properties include sodium iodide salt (Majid et al., 2009), silicon oil and glycol (Tomoji etbal., 2013; Yoshida et al., 2014), Polyamide particles as scatters (Fhrmann et al., 2016). Recently, propylene glycol and polyethylene glycol were found to provide a good combination with water and glycerol as BMF mixture fluid while poly (4-methylstyrene) was used as scatter particles to mimic the red blood cells (Oglat et al., 2017; Oglat et al., 2018). A good BMF must have physical properties (density, viscosity and particle size) and acoustic properties (speed of sound and attenuation) closed to the internationally acceptable standards (Yoshida et al., 2014; Oglat et al., 2018).

In this paper, we have discussed another method for preparing a BMF made up of water, propylene glycol, glucose and poly (4-methylstyrene) as scatter particles. The new item introduced is glucose as part of the ternary mixture fluid with a bulk density of $1.50 \mathrm{~g} / \mathrm{cm} 3$ higher than the densities of water $\left(0.998 \mathrm{~g} / \mathrm{cm}^{3}\right)$ and propylene glycol $\left(1.036 \mathrm{~g} / \mathrm{cm}^{3}\right)$. The choice 
62 of glucose is justified because it increases the acoustic and physical properties of the mixture

63 fluid until the right amount produces a BMF fluid with properties accepted internationally. A real

64 human blood contains glucose as part of the components of its plasma and serum, the presence of

65 high level of glucose in the blood plasma $(\geq \mathbf{1 3 0} \mathbf{m g} / \mathbf{d l})$ makes it hyperglycemic (diabetic) and

66 a risk factor of cardiovascular disease (Rita et al., 2015; Flora \& Nayak, 2019; Hamid et al.,

67 2019; Bochra et al., 2020). Blood sugar (glucose) plays an important role as the energy

68 requirement of the body. Excess of glucose in the blood results to diabetes which can be

69 categorized as type 1 or type 2 depending on its severity on human health. This makes it

70 important to have a BMF with glucose as a component of the mixture fluid to be used for in-vitro

71 ultrasound flow measurements.

$72 \quad 2$ Materials and Methods

73 A Materials

74

The materials used for this research are grouped under chemical items and hard ware

75 apparatus.

76 I Chemical Items

77 The chemical components of the BMF include the following;

78 a. Distilled water: A distilled water (density of $0.998 \mathrm{~g} / \mathrm{cm}^{3}$ ) was used as the largest proportion

79 of the fluid mixture to mimic the water component of the real blood plasma

80 b. Sigma Aldrich Propylene glycol (PG): This is a viscous organic compound that is colorless

81 and nearly odorless with a faint sweet taste represented by the chemical formula, 
$\mathrm{CH}_{3} \mathrm{CH}(\mathrm{OH}) \mathrm{CH}_{2} \mathrm{OH}$. It is soluble in water and other organic solvents with a molecular mass of $76.09 \mathrm{~g} / \mathrm{mol}$, density of $1.036 \mathrm{~g} / \mathrm{cm}^{3}$ and viscosity of 0.042 pa.s (Haynes, 2016). PG also known as propan-1,2-diol is used for production of polymers, in various edible items such as coffee-based drinks, liquids sweeteners and ice cream, but for this research, it was used to achieve the physical and acoustic properties of a mixture fluid for BMF preparation.

c. $\mathrm{D}(+)$-Glucose (DG)(Merck, Germany): Glucose is a simple sugar with the molecular formula $\mathrm{C}_{6} \mathrm{H}_{12} \mathrm{O}_{6}$ as the most abundant monosaccharide (Bastioli, 2014), mainly made by plants and most algae during photosynthesis from water and carbon dioxide using energy from the sunlight. It has a molar mass of $180.156 \mathrm{~g} / \mathrm{mol}$ and a bulk density of $1.50 \mathrm{~g} / \mathrm{cm}^{3}$, soluble in water with applications as food sweeteners, in the industries and in medicine. For this research, glucose was used also to study the physical and acoustic properties of BMF mixture fluid and to find out its effect on BMF flow velocity in the carotid artery phantom.

d. Poly 4-methylstyrene (Sigma Aldrich, Germany): This substance is a mixture of polymer (styrene) and monomer (methyl) used for making polymers and plastics. It is used as a scatter particle in this research because it has a combined influence as a Rayleigh-scattering with a density of $1.040 \mathrm{~g} / \mathrm{cm}^{3}$ and particle size of $3-8 \mu m$ (Oglat et al., 2018). The ability for this substance to remain suspended (neutrally buoyant) in the BMF mixture fluid, its spherical nature which avoids clothing inside a vessel during flow, its closeness to the density of BMF and its commercial availability makes it a good choice as a scatter particle since it is insoluble in liquid substances.

e. Benzalkonium Chloride (Sigma Aldrich, Germany): This is an organic salt of cationic surfactant type classified as a quaternary ammonium compound having a density of 0.98 $\mathrm{g} / \mathrm{cm}^{3}$ with variable chemical formula, molar mass and very soluble in water. Its solutions 
are fast-acting biocidal agents with a moderately long duration of action used as fungicides, medical surgical device disinfectants and anti-bacterial agent.

\section{Hard ware apparatus}

The apparatus used in this research are the chemical balance to measure the mass of substances, electric density meter to measure fluid density, electric rotational viscometer (ERV) to measure viscosity and A-scan GAMPT (German Society for Applied Medical Physics and Technology) to measure acoustic properties. Other apparatus are the magnetic stirrer hot plate and bar for heating and stirring, vacuum pump for degassing, beakers, measuring cylinders, thermometer and a dropper.

\section{B Methods}

\section{Blood Mimicking Fluid (BMF) Preparation}

The BMF was prepared in the medical and solid state physics laboratories of Universiti Sains Malaysia as outline through the following steps:

a. First, the glass beaker with size about twice the volume of the BMF was washed with distilled water and wiped clean with a tissue paper. The choice of this size of beaker was to avoid the overflowing of the fluid while stirring. This was followed by placing a magnetic stirrer (with size commensurate with the size of the beaker) inside the beaker.

b. 90 weight percentage (wt $\%$ ) of distilled water was measured using a measuring cylinder and $5 \mathrm{wt} \%$ of PG (Oglat et al., 2017) was weight as well as $5 \mathrm{wt} \%$ of DG in a fume cupboard using a chemical balance. The distilled water was first poured into the beaker, followed by the DG with thorough stirring to ensure that the DG dissolves completely. 
Finally, the PG was added and the whole component placed on a magnetic stirrer hot plate as shown in figure 1a.

c. The stirring plate was set to operate at 700 revolutions per minute (rpm) for 20 minutes at a temperature of $37^{\circ} \mathrm{C}$ after which the vacuum pump is used to degas the fluid for about 30 minutes.

d. The procedures above were repeated four more times but with different wt $\%$ of distilled water and DG while the amount of PG remained fixed at $5 \mathrm{wt} \%$. The five (5) samples (figure 1b) together with $100 \mathrm{wt} \%$ distilled water were then tested for their densities, viscosities, speed of sound and attenuation properties

e. A linear relationship was established using the statistical package for social sciences (SPSS) soft ware between the density and the amount of DG in the fluids resulting to the equation:

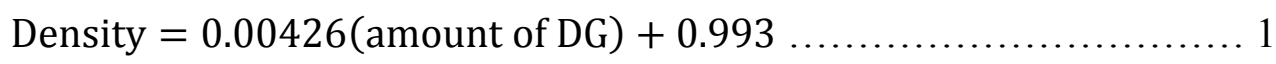

With equation $1,11 \mathrm{wt} \%$ of DG by weight was required to mix with $5 \mathrm{wt} \%$ of PG and 84 $\mathrm{wt} \%$ of distilled water to produce exactly a mixture fluid with a density of $1.040 \mathrm{~g} / \mathrm{cm}^{3}$, a value required to match with the density of poly (4-methylstyrene) scatter. This allows the scatter particles to remain neutrally buoyant in the fluid mixture.

f. Finally, the hyperglycemic BMF was produced by mixing the required amount of scatter particles, poly 4-methylstyrene $(0.8 \mathrm{wt} \%)$ with the mixture fluid (5 wt $\%$ of PG, 11 $\mathrm{wt} \%$ of DG and $84 \mathrm{wt} \%$ of water). The BMF was then placed on the stirrer plate and two drops of $50 \mathrm{wt} \%$ anti-fungal agent (Benzalkonium Chloride) was added, it was then stirred for about 30 minutes and degassed for about an hour to remove any air bubbles. 


\section{Measurements of Density and Viscosity}

The densities of the BMF fluids were measured using a portable Density Meter

(DMA 35). The strip attached to the meter was pressed down and dipped in the fluid, and then it was released to draw up the fluid inside the strip by suction pressure, while the density reading was recorded automatically by the meter in just few seconds. The density increased with decrease in temperature, therefore the liquid was heated up to about $40^{\circ} \mathrm{C}$ before dipping the meter strip. The readings were measured when the temperature was exactly at $37^{0} \mathrm{C}$, the normal human body temperature.

About $700 \mathrm{~cm}^{3}$ of each BMF fluid was required for the viscosity measurements. The spindle L1 was selected for viscous liquid, it was attached to the ERV and then lowered into the fluid (figure 1c) while the ERV was switched on. The spindle rotates inside the liquid for few minutes until a steady value of the viscosity was recorded due to the viscous resistance from the fluid (Kim et al., 2015; Ihm et al., 2020)

\section{Measurements of speed of sound, Attenuation and Backscatter power}

The speed of sound was measured by pulse echo (PE) method using the A-scan Gampt machine. The arrangement for this measurement is shown in (figure 2) where the time of flight (TOF) between the highest two peaks of the transmitted and reflected waves was measured. For good accuracy, the protective layer thickness of the probe was first calculated and added to the distance between the walls of the vessel containing the liquid. This was done by using two acrylic plates of thicknesses $40 \mathrm{~mm}$ and $80 \mathrm{~mm}$ with the same speed of sound of $2700 \mathrm{~m} / \mathrm{s}$. The Pulse echo method using A-scan GAMPT technique was able to provide time of flight for the 
169 two plates which was used to calculate the thickness of the protective layer of the probe using the

170 equation:

171

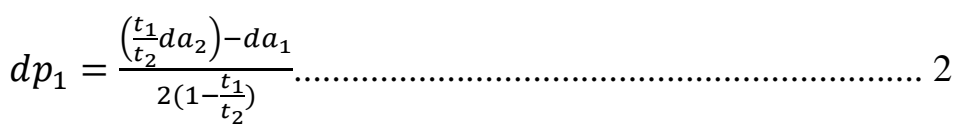

172 Where $d p_{1}$ is the thickness of the transducer protective layer, $d a_{1}$ is the thickness of the acrylic

173 plate $(40 \mathrm{~mm}), d a_{2}$ is the thickness of the acrylic plate $(80 \mathrm{~mm}), t_{1}$ is the time of flight through

174 the plate $(40 \mathrm{~mm})$ and $t_{2}$ is the time of flight through the plate $(80 \mathrm{~mm})$. The values for the speed

175 of sound for the liquids were calculated using the equation:

176

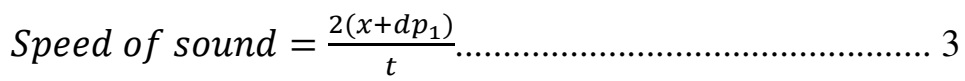

177 Where $x$ is the distance between the walls of the vessel containing the mixture liquid and $t$ is the 178 time of flight

The amplitudes of the highest two similar peaks were also measured and the attenuation coefficients $(\alpha)$ were also calculated using the attenuation equation:

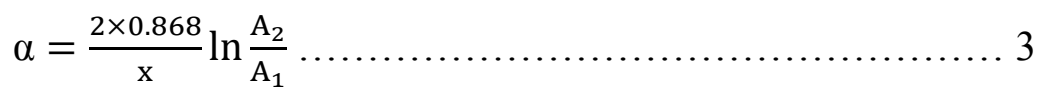

182 Such that $A_{1}$ and $A_{2}$ are the amplitudes of the two highest but similar wave peaks respectively 183 and $x$ is the distance.

The backscatter power of the BMF was measured at different radio frequency signals by 185 calculating the average power spectrum through applying the Fast Fourier Transform (FFT) 186 generated by the A-scan GAMPT software at $5 \mathrm{MHz}$. This was done at different concentrations 187 of the scatter particles poly (4-methylstyrene) and cholesterol to find out if the BMF simulates 
188 the real human blood. The backscatter coefficients were directly read on the screen of the A-

189 mode PE technique during the ultrasound scanning.

190

191

192

193

194

195

196

197

198

199

200

201

202

203

204

205

206

207

208

209

\section{Ultrasound measurements of Flow velocity and Indices}

The BMF was tested by running it through an $8.0 \mathrm{~mm}$ lumen diameter common carotid artery wall-less phantom prepared with a konjac-carrageenan and gelatin based tissue mimicking material ((Ammar et al., 2018). The BMF was pumped with the aid of a gear pump (multi-flow GAMPT) at a steady flow rate of $1500 \mathrm{ml} / \mathrm{min}$ to measure the flow properties using a digital Hitachi ultrasound scanner connected with a linear array transducer (EUP-L74M).

\section{Results and Discussion}

The result of changing the amount of DG with a fixed amount of PG shows that the density, viscosity, speed of sound and attenuation increased linearly (Tomoji et al., 2013; Yoshida et al., 2014; Oglat et al., 2017; Oglat et al., 2018) with increase in the percentage weight of the DG as seen in table 1 and figure 3. This was made possible because the density of DG $\left(1.50 \mathrm{~g} / \mathrm{cm}^{3}\right)$ is higher than those of water $\left(0.998 \mathrm{~g} / \mathrm{cm}^{3}\right)$ and PG $\left(1.036 \mathrm{~g} / \mathrm{cm}^{3}\right)$. We had to put the amount of PG fixed at $5 \mathrm{wt} \%$ because its density is less than the density of the scatter particle (poly 4-methystyrene) whose density is $1.040 \mathrm{~g} / \mathrm{cm}^{3}$. By implication, it means that increasing the amount of DG increased the densities of water and PG until a suitable amount of DG gave the required density of the mixture fluid that enabled the scatter particle to stay neutrally buoyant in the fluid because they have the same densities. By equation $1,11 \mathrm{wt} \%$ of DG $(91.52 \mathrm{~g})$ was required to mix with $84 \mathrm{wt} \%$ of water $\left(700 \mathrm{~cm}^{3}\right)$ and $5 \mathrm{wt} \%$ of PG $\left(40 \mathrm{~cm}^{3}\right)$ to obtain a suitable mixture fluid which in turn was used to mix with $0.8 \mathrm{wt} \%$ of poly 4 -methly styrene scatter $(6.656 \mathrm{~g})$ to produce $800 \mathrm{~cm}^{3}$ of the BMF. This result means that $91.52 \mathrm{~g}$ of DG was mixed with 
$210740 \mathrm{~cm}^{3}$ of fluid to give a good mixture fluid for the hyperglycemic BMF. It also implies that the 211 amount of glucose in the BMF is $12,369 \mathrm{mg} / \mathrm{dl}$ which is far much higher than the normal range

212 of glucose level of less than $125 \mathrm{mg} / \mathrm{dl}$ (Poretsky, 2017) in the healthy human blood.

For Doppler flow test object, it is relevant that the BMF backscatter power be well 214 established, reconfirmed and stable. The ultrasound backscatter from the BMF should be close to 215 that of flowing human blood. This will make measurements of penetration depth and sensitivity 216 very reliable (Evan \& James, 1988). In this research, we used the PE method which involves 217 using a single plane transducer as emitter and receiver to measure the backscatter power at 218 different concentrations of the Poly (4-methystyrene) scatter particles in the BMF. The mean 219 power spectrum was calculated by performing FFT on the radio frequency (RF) signals while the 220 backscatter power in decibel $(\mathrm{dB})$ was determined by the ratio of the mean power at $5 \mathrm{MHz}$ from 221 the flowing BMF. Results showed a linear dependence of backscatter power on increasing the 222 particle concentrations of Poly (4-methystyrene) (Oglat et al., 2018) as shown in figure 4.

223 The BMF prepared has a density of $1.040 \mathrm{~g} / \mathrm{cm}^{3}$, viscosity of $4.30 \mathrm{mpa} . \mathrm{s}$, speed of sound 224 of $1580 \mathrm{~m} / \mathrm{s}$ and an attenuation of $0.017 \mathrm{~dB} / \mathrm{cm}$ at $5 \mathrm{MHz}$, which are within the acceptable ranges 225 for the physical and acoustic properties of a BMF by the International Electrochemical 226 Commission (IEC) for Doppler ultrasound flow phantoms (Ramnarine et al., 1998; Browne et 227 al., 2003; Samavat \& Evans, 2006; Yoshida et al., 2012; Yoshida et al., 2014). Results of flow 228 velocity measurements (figure 5) show that the peak systolic flow velocity $(74.1 \mathrm{~cm} / \mathrm{s}$ ), end 229 diastolic velocity $(23.2 \mathrm{~cm} / \mathrm{s})$, resistivity index (0.69) and pulsatility index (1.06) were within 230 accepted limits (Oglat et al., 2018). This observation suggest that even though the BMF is 231 hyperglycemic, its hemodynamic indices are within the normal range for a healthy blood flow 
232 implying that high blood sugar does not affect the flow of blood in the human carotid artery

233 since this type of flow is non-Newtonian in-vivo but Newtonian in-vitro (Ozlem et al., 2015).

2344 Conclusion

235

236

237

238

239

240

241 suitable for ultrasound in-vitro studies. The preparation took just few minutes and the cost of

242 producing it is very low compared to commercially available BMF phantoms. The BMF lasted

243 for about 3 months due to the addition of a preservative or anti-fungal agent to the fluid.

244 Ethics approval and consent to participate

245 Not applicable

246 Consent for publication

247 Not applicable

248 Availability of data and materials

249 All data generated or analyzed during this study are included in this published article (and its 250 supplementary information files). 
253 Competing interests

254 The authors declare that they have no competing interests.

255 Funding

256 No funding

257 Authors' contributions

258 Prof. MZ initiated the research, provided support (under the grant number 1001/PFIZIK/822173)

259 and supervisory role. Dr NS gave technical advice, support (under the grant number

260 1001/PFIZIK/822173) and editing of the manuscript. Mr DK performed the experiment and

261 contributed in drafting of the manuscript. Dr SA and Dr AA contributed with essential materials

262 needed for the manuscript drafting and also participated in prove reading the manuscript. All

263 authors read and approved the final manuscript

\section{Acknowledgment}

265 We thank our colleagues from Universiti Sains Malaysia, Medical physics and Radiation

266 Science department, who provided insight and expertise that made this research a success. 
273

274

275

276

277

278

279

280

281

282

283

284

285

286

287

288

289

290

291

292

293

\section{References}

Ammar, A. O., Matjafri, M., Suardi, N., Oqlat, M. A., Oqlat, A. A., Abdelrahman, M. A., et al., . Characterization and Construction of a Robust and Elastic Wall-Less Flow Phantom for High Pressure Flow Rate Using Doppler Ultrasound Applications. Natural and Engineering Sciences. 2018; 3(3), p. 359-377. https://doi.org/10.28978/nesciences.468972

Bastioli, C. Handbook of Biodegradable Polymers. 2nd ed. United Kingdom, 2014.

Bochra, Z., Paul, B., Maria, D., Mariam, E. M., Caroline, H. N., Christian, S., et al. Type 2 Diabetes Mellitus and Impact of Heart Failure on Prognosis Compared to Other Cardiovascular Diseases. Circulation: Cardiovascular Quality and Outcomes. 2020; 13(7). https://doi.org/https://doi.org/10.1161/CIRCOUTCOMES.119.006260

Browne, J. E., Ramnarine, K. V., Watson, A. J., Hoskins, P. R. (2003). Assessment of the acoustic properties of common tissue-mimicking test phantoms. In Ultrasound in Medicine and Biology. 2003; 29(7), p. 1053-1060. https://doi.org/10.1016/S0301-5629(03)00053-X

Evan, J. B., James, A. Z. Performance tests of Doppler ultrasound equipment with a tissue and blood-mimicking phantom. J Ultrasound Med. 1998; 7, p. 137-147.

Fhrmann, T., Schlesinger, A., Schultz, K. J. A blood mimicking fluid for clot-detection experiments with ultrasound. Ultraschall Med. 2016; 37(5), p. 1-8. https://doi.org/10.1055/s-0036-1587737

Flora, G. D., Nayak, M. K. A Brief Review of Cardiovascular Diseases, Associated Risk Factor. Current Pharmaceutical Design. 2019; 25(38), p. 4063-4084. https://doi.org/https://doi.org/10.2174/1381612825666190925163827 
294 Hamid, S., Groot, W., Pavlova, M. Trends in cardiovascular diseases and associated risks in

295

296

297

298

299

300

301

302

303

304

305

306

307

308 sub-Saharan Africa : a review of the evidence for Ghana, Nigeria, South Africa, Sudan and Tanzania. The Aging Male. 2019; 22(3), p. 169-176.

https://doi.org/10.1080/13685538.2019.1582621

Harin, N. I., Ince, D. G. Moderately Nonlinear Ultrasound Propagation in Blood-Mimicking Fluid. Ultrasound in Med. \& Biol. 2004; 30(4), p. 501-509. https://doi.org/10.1016/j.ultrasmedbio.2004.01.003

Haynes, W. M. CRC Handbook of Chemistry and Physics. 96th ed, California, 2016.

Ihm, C., Lee, D., Ahn, K. H., Oh, J. S. Viscosity Measurement of Whole Blood with Parallel Plate Rheometers. The Korean BioChip Society and Springer. 2020; p. 1-6. https://doi.org/10.1007/s13206-020-4202-7

Kim, Y. R., Ka, Y. M., Nam, C. C., Eui. Y. K., Lee, D. W. Measuring Blood Viscosity in Normal Tension Glaucoma Patients. J Korean Ophthalmol Soc. 2015; 56(5), p. 753-758.

Lubbers, J. Application of a new blood-mimicking Doppler test object. European Journal of Ultrasound. 1999; 8266(99), p. 267-276.

Majid, Y. Y., David, W. H., Tamie, L. P. Deriving a blood-mimicking fluid for particle image velocimetry in sylgard-184 vascular models - IEEE Conference Publication. Annual International Conference of the IEEE Engineering in Medicine and Biology Society. 2009, https://doi.org/10.1109/IEMBS.2009.5334175

Meagher, S., Poepping, T. L., Ramnarine, K. V., Black, R. A., Hoskins, P. R. Anatomical flow phantoms of the nonplanar carotid bifurcation, Part II: Experimental validation with 
Doppler ultrasound. Ultrasound in Medicine and Biology. 2007; 33(2), 303-310. https://doi.org/10.1016/j.ultrasmedbio.2006.08.004

Oglat, A. A., Matjafri, M. Z., Suardi, N., Abdelrahman, M. A., Oqlat, M. A., Oqlat, A. A. A new scatter particle and mixture fluid for preparing blood mimicking fluid for wall-less flow phantom. In Journal of Medical Ultrasound. 2018; 26(3), p. 134-142. https://doi.org/10.4103/JMU.JMU_7_18

Oglat, A. A., Matjafri, M. Z., Suardi, N., Mostafa, A. Acoustical and Physical Characteristic of a New Blood Mimicking Fluid Phantom. The International Conference of Solid State Science and Technology, 2018. https://doi.org/10.1088/1742-6596/1083/1/012010

Oglat, A. A., Matjafri, M. Z., Suardi, N., Oqlat, M. A., Abdelrahman, M. A., Oqlat, A. A. A review of medical doppler ultrasonography of blood flow in general and especially in common carotid artery. In Journal of Medical Ultrasound. 2018; 26(1), p. 3-13. https://doi.org/10.4103/JMU.JMU_11_17

Oglat, A. A., Matjafri, M. Z., Suardi, N., Oqlat, M. A., Oqlat, A. A., Abdelrahman, M. A. a New Blood Mimicking Fluid Using Propylene Glycol and Their Properties for a Flow Phantom Test of Medical Doppler Ultrasound. In International Journal of Chemistry. 2017; 2(5), p. $220-231$.

Ozlem, Y., Daniel, O., Alexander, T. W., Paul, C. J., Pedro, C. (2015). Perfusion pressure and blood flow determine microvascular apparent viscosity. Experimental Physiology. 2015; 100(8), p. 977-987. https://doi.org/10.1113/EP085101

Poretsky, L. Principles of Diabetes Mellitus. 3rd ed, New York, 2017. 
337 Ramnarine, K. U., Nderson, T. O., Oskins, P. E. Construction and Geometric Stability of 338

Ramnarine, K. V., Nassiri, D. K., Hoskins, P. R., Lubbers, J. Validation of a new bloodmimicking fluid for use in Doppler flow test objects. In Ultrasound in Medicine and Biology. 1998; 24(3), p. 451-459. https://doi.org/10.1016/S0301-5629(97)00277-9

343 344 345 346 347 348 349 350 351 352 353 354 355 356
Rickey, D. W., Picot, P. A., Christopher, D. A., Fenster, A. A wall-less vessel phantom for Doppler ultrasound studies. Ultrasound in Medicine and Biology. 1995; 21(9), p. 11631176. https://doi.org/10.1016/0301-5629(95)00044-5

Rita, C. F., Ricardo, S. N., Hector, E. G., Fernanda, G. T., Adriana, B. F., Junior, L. S. Detecting alterations of glucose and lipid components in human serum by near-infrared Raman spectroscopy. Res. Biomed. Eng. 2015; 31(2), p. 1-8 https://doi.org/https://doi.org/10.1590/2446-4740.0593

Samavat, H., Evans, J.A. An ideal blood mimicking fluid for doppler ultrasound phantoms. Journal of Medical Physics. 2006; 31(4), p. 275-278.

Tomoji, Y., Kazuis, K.S., Toshio, K. Blood Mimicking Fluid Using Polyethylene Glycol Aqueous Solution and Their Physical Properties. Proceedings of Symposium on UltrasonicElectronic. 2013; p. 319-320.

Yoshida, A.K., Tomoji, S., Kazuishi, K., Toshio, Y., Yasukawa, K. Blood-Mimicking Fluid for Testing Ultrasonic Diagnostic Instrument Blood-Mimicking Fluid for Testing Ultrasonic 
357 Diagnostic Instrument. Japanese Journal of Applied Physics. 2012; 51(7).

$358 \quad$ https://doi.org/10.1143/JJAP.51.07GF18

359 Yoshida, T., Sato, K., Kondo, T. Blood-mimicking fluid using glycols aqueous solution and

360 their physical properties. Japanese Journal of Applied Physics. 2014; 53(75), p. 8-13.

361 https://doi.org/http://dx.doi.org/10.7567/JJAP.53.07KF0

362

363

364

365

366

367

368

369

370

371

372

373

374 
375

376

377

\begin{tabular}{|c|c|c|c|c|c|c|c|}
\hline S/No. & $\begin{array}{l}\text { Distilled water } \\
\text { (wt\%) }\end{array}$ & $\begin{array}{l}\text { Propylene } \\
\text { Glycol (wt\%) }\end{array}$ & $\begin{array}{l}\mathrm{D}(+) \text {-Glucose } \\
\text { (wt\%) }\end{array}$ & $\begin{array}{l}\text { Density } \\
\left(\mathrm{g} / \mathrm{cm}^{3}\right)\end{array}$ & $\begin{array}{l}\text { Viscosity } \\
\text { (mpa.s) }\end{array}$ & $\begin{array}{l}\text { Speed of } \\
\text { Sound }(\mathrm{m} / \mathrm{s})\end{array}$ & $\begin{array}{l}\text { Attenuation } \\
(\mathrm{dB} / \mathrm{cm})\end{array}$ \\
\hline 1 & 100 & 0 & 0 & 0.993 & 2.8 & 1513.4 & 0.0046 \\
\hline 2 & 90 & 5 & 5 & 1.016 & 3.4 & 1549.3 & 0.0065 \\
\hline 3 & 85 & 5 & 10 & 1.035 & 3.8 & $1566 . .4$ & 0.0105 \\
\hline 4 & 80 & 5 & 15 & 1.057 & 4.4 & 1588.4 & 0.0190 \\
\hline 5 & 75 & 5 & 20 & 1.079 & 5.2 & 1614.1 & 0.0194 \\
\hline 6 & 70 & 5 & 25 & 1.100 & 5.8 & 1634.3 & 0.0198 \\
\hline
\end{tabular}

378

379

380

381

382

383

384

385 


\section{$387 \quad$ Figure Legends}

388 Figure 1: (a) Magnetic stirring mixing the components properly and to become homogeneous 389 (b)Density meter (DMA 35) to measure the density of the aqueous solutions (c) Rotational Viscosity Meter measuring the viscosity of the mixture fluids

391 Figure 2: Measurement of the acoustic properties of solutions using the A-scan Gampt technique

392 Figure 3: Linear graphical representation of relationship between Density and D(+)-Glucose 393 concentration (DGCon)

394 Figure 4: Relative backscatter from BMF under uniform flow plotted against particle concentration for Poly (4-methylstyrene) particles of size 3-8 $\boldsymbol{\mu} \mathrm{m}$.

396 Figure 5: BMF flow velocity and indices through $8.0 \mathrm{~mm}$ common carotid artery phantom 
Figures

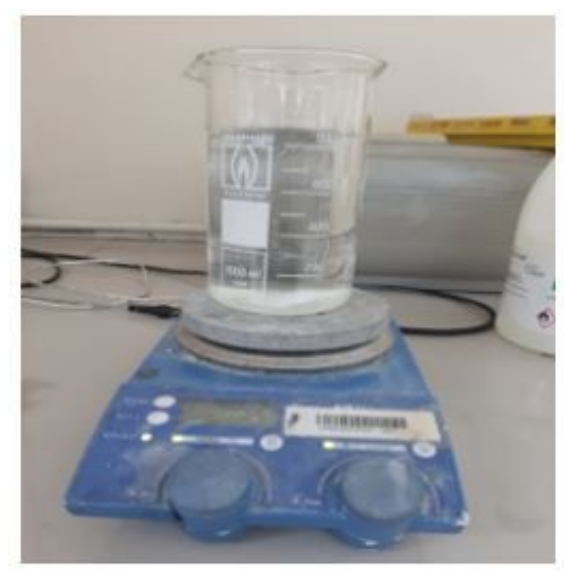

(a)

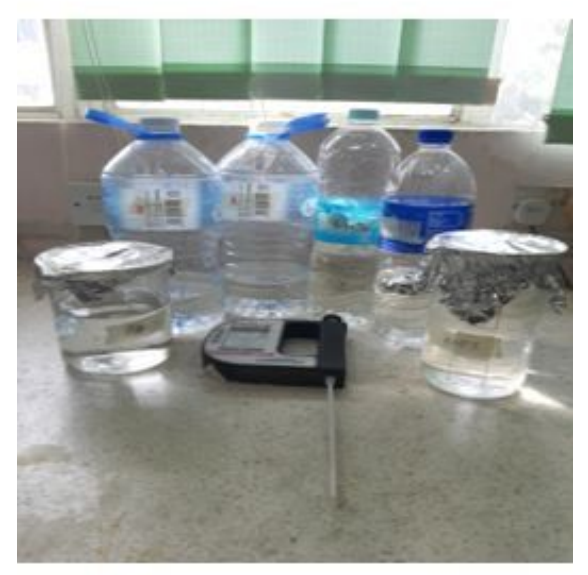

(b)

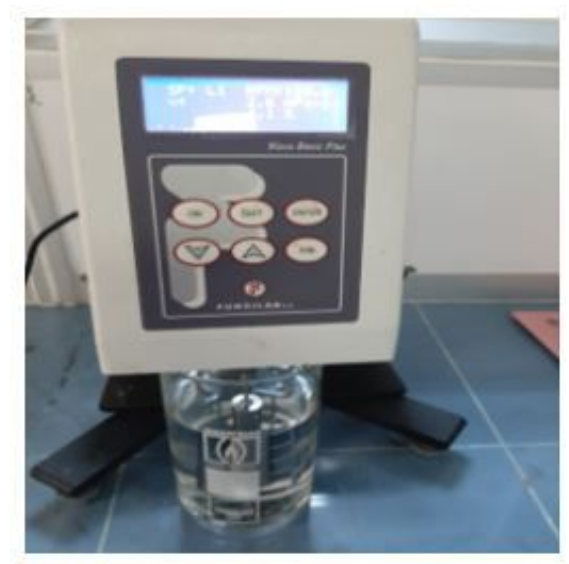

(c)

\section{Figure 1}

(a) Magnetic stirring mixing the components properly and to become homogeneous (b) Density meter (DMA 35) to measure the density of the aqueous solutions, (c) Rotational Viscosity Meter measuring the viscosity of the mixture fluids 


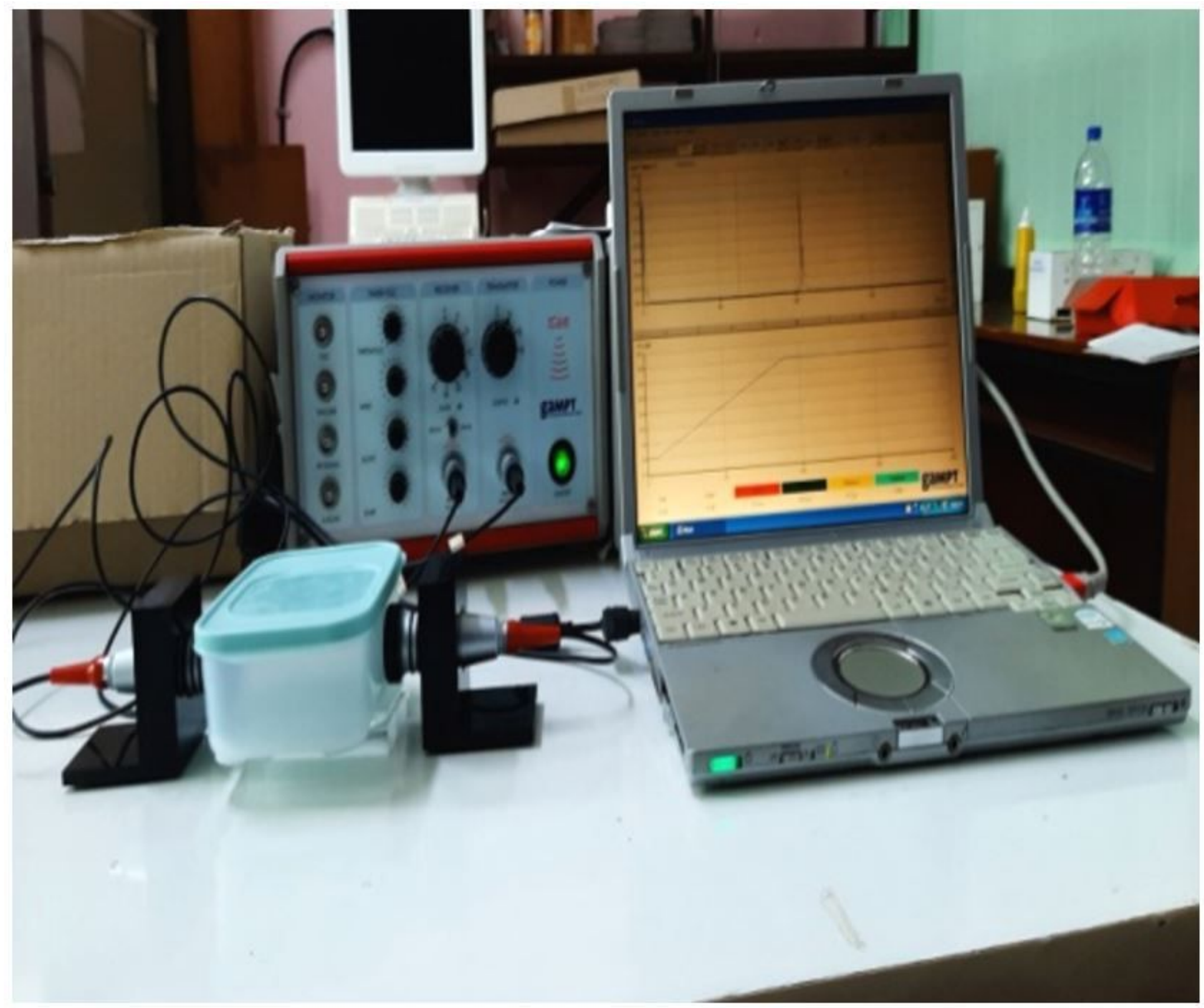

Figure 2

Measurement of the acoustic properties of solutions using the A-scan Gampt technique 


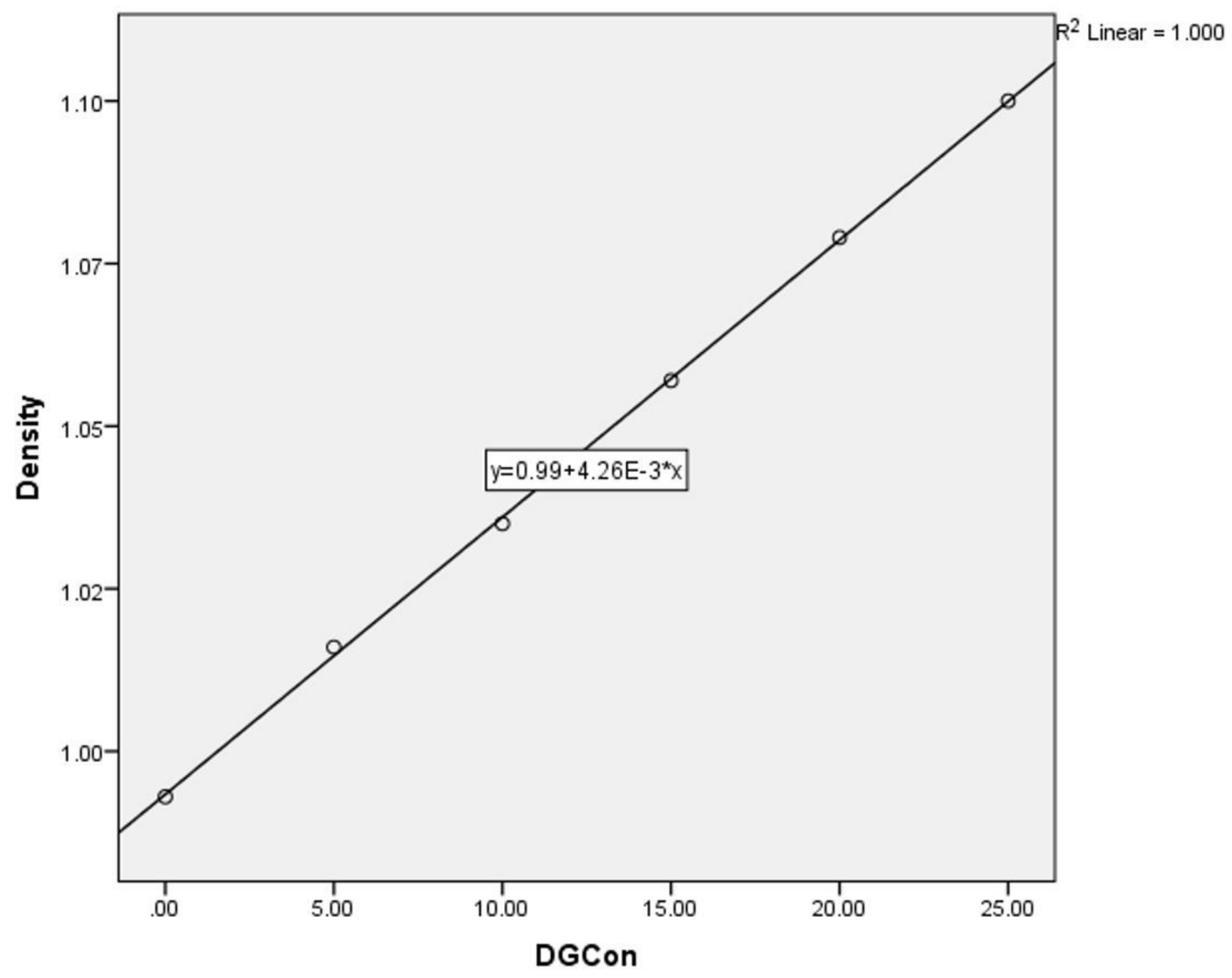

Figure 3

Linear graphical representation of relationship between Density and D(+)-Glucose concentration (DGCon) 


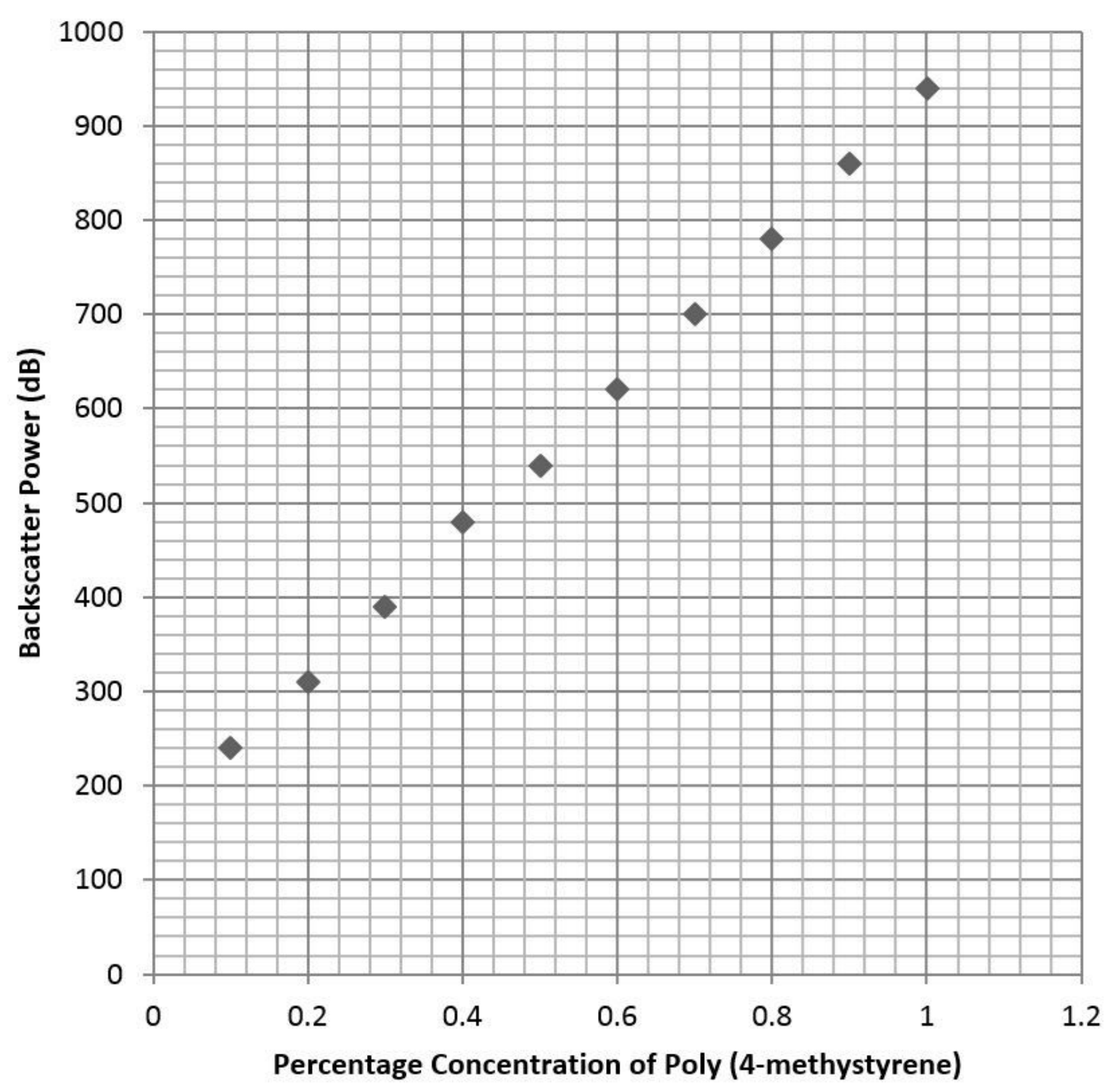

Figure 4

Relative backscatter from BMF under uniform flow plotted against particle concentration for Poly (4methylstyrene) particles of size 3-8 $\mu \mathrm{m}$. 


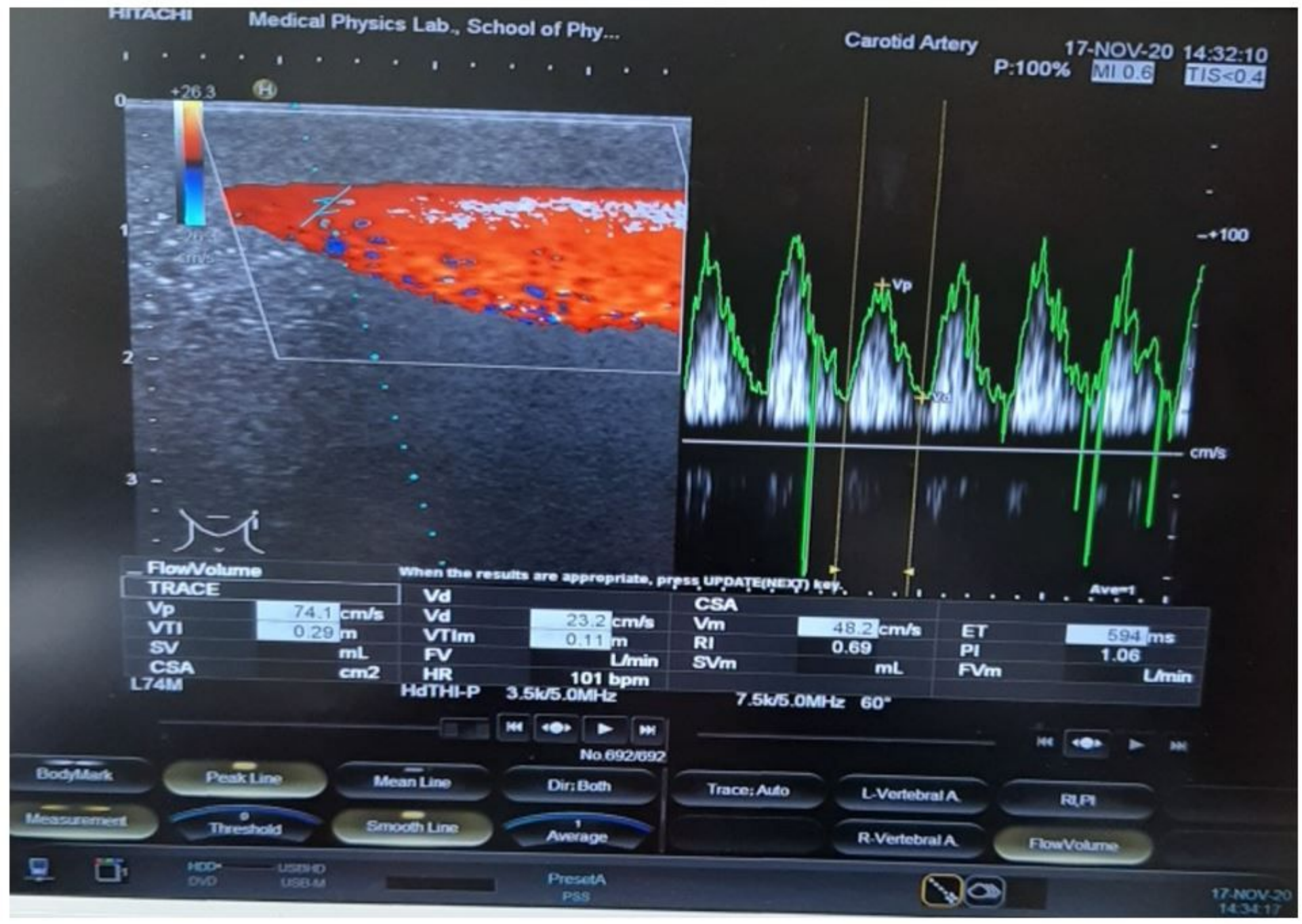

Figure 5

BMF flow velocity and indices through $8.0 \mathrm{~mm}$ common carotid artery phantom 